Miroslav S. Milićević*1

\title{
DOPUNA 3D ROZENTALOVIH JEDNAČINA RADI OPTIMIZACIJE VEZE IZMEĐU KRITIČNOG VREMENA HLAĐENJA I TEMPERATURE PREDGREVANJA KOD ELEKTROLUČNOG ZAVARIVANJA
}

\section{Originalni naučni rad / Original scientific paper UDK / UDC: 621.791.753}

\section{Rad primljen / Paper received:}

Novembar 2018.

Ključne reči: temperatura predgrevanja, vreme hlađenja, zavarivanje, toplota

\section{Rezime}

Ovde se predstavlja poboljšanje izračunavanja veličina kod elektrolučnog zavarivanja, kao što su temperatura predgrevanja i kritičnog vremena hlađenja $t_{8 / 5}$. Ova istraživanja su rezultirala studiranjem teorije termike kod elektrolučnog zavarivanja i praktičnim radom, nakon čega su pronađeni načini da se rešavanje navedenih problema omogućava uvođenjem novih grafičkih i analitičkih zavisnosti. Provera navedenih rešenja je obavljena numeričkim primerima.

\section{Uvod}

Rad se bazira na proučenoj relevantnoj literaturi [117]. U ovoj oblasti postoje radovi koji su bazni i oni su prezentovani u literaturi [18-22]. Ovu teoriju primenjuju radovi autora ovog rada [23-27] publikovani višedecenijskim teoretskim i primenjenim istraživanjima na polju zavarivanja.
Adresa autora / Author's address:

1 Prof. Dr, Univerzitet u Beogradu,Visoka tehnička škola, Beograd

KKorespodentni autor; E-mail: milicevic.miroslav@mts.rs

Key words: preheating temperature, cooling time, welding, heat

\section{Abstract}

Here is an improvement in the calculation of the sizes for arc welding, such as preheating temperature and critical cooling time $t_{8 / 5}$. These studies resulted in the study of thermodynamic theory in arc welding and practical work, after which ways were found to solve these problems by introducing new graphic and analytical dependencies. Checking the above solutions is done numerically.

Glavne veličine su određene izračunavanjem potrebne snage za zavarivanje određenog čeličnog proizvoda, određenom brzinom zavarivanja.

Kod elektrolučnog zavarivanja, gde su na sl.1 prikazane dve čelične ploče koje se zavaruju, uspostaviće se model radi definisanja temperaturnog polja u ploči debljine d i širine D.

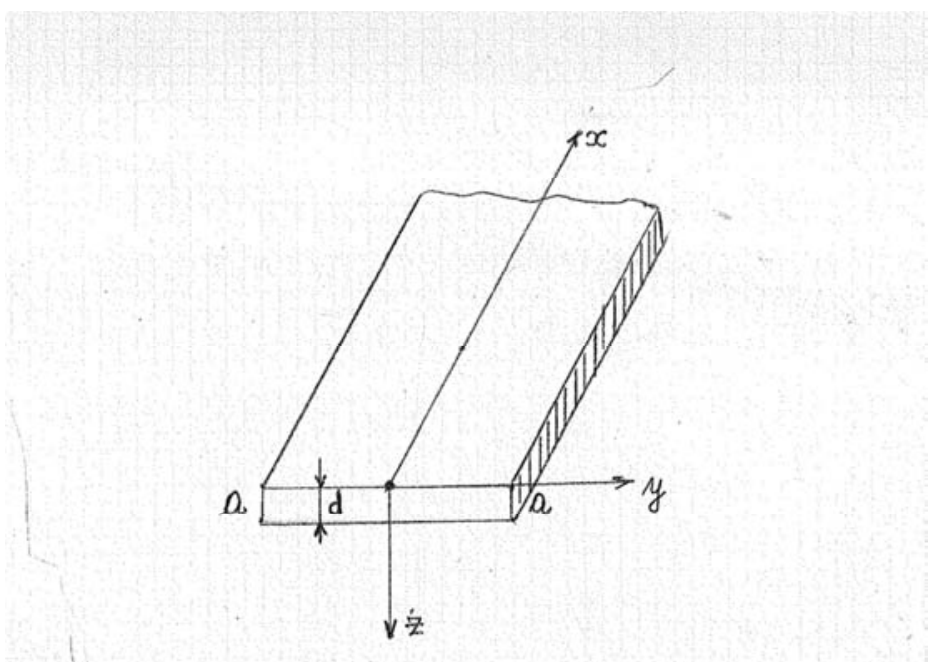

SI.1. Detalj dveju čeličnih ploča koje se zavaruju 
$U$ ploči temperatura $T$ je po debljini približno ujednačena i nezavisna od ose $z$, te je $\frac{\partial T}{\partial z}=0$.

Uz pretpostavku da je muđudejstvo površina toplotno provodnog tela $\mathrm{u}$ odnosu na okolinu adijabatsko, stoga toplotni fluks kroz granicu izostaje

$$
Q_{n}=0 \quad i \quad \frac{\partial T}{\partial n}=0,
$$

$\mathrm{n}$ je normala na površinu a.

Obe strane metalne ploče se smatraju adijabatskim jer je

$$
\frac{\alpha}{\lambda} \rightarrow 0
$$

gde je a koeficijent prelaza toplote i $\lambda$ koeficijent toplotne provodnosti. Zavarivanje ide duž ose $x$, te se izvor smatra pokretnim. Izvor toplote je element zapremine tela preseka dxdy i visine d kao debljine. To se temperaturno polje linijskog izvora može dobiti primenom principa slaganja, što posle integracije elemenata priraštaja temperature po $[18,19]$ je

$$
T(t)=\int_{0}^{t} d T\left(\mathrm{t}^{\prime}\right)
$$

gde je $\mathrm{t}$ interval vremena $\mathrm{u}$ kome deluje izvor toplote $a t^{\prime}$ je proizvoljan moment vremena. Distribucija temperature u ploči koja se zavaruje može se opisati Furijeovom jednačinom

$$
\frac{\partial T}{\partial t}=a\left(\frac{\partial^{2} T}{\partial x^{2}}+\frac{\partial^{2} T}{\partial y^{2}}\right)
$$

gde je $a=\frac{\lambda}{c \gamma}$ - koeficijent temperaturne provodnosti, c - specifična toplota i $\gamma$ specifična težina.

Koristeći iskustva iz $[20,21]$ rešenje Furijeove jednačine se svodi na

$$
\begin{gathered}
\mathrm{T}(\mathrm{r}, \mathrm{x})=\frac{\mathrm{q}}{2 \pi \lambda \mathrm{d}} \exp \left(-\frac{\mathrm{vx}}{2 \mathrm{a}}\right) \mathrm{K}_{0}\left[\mathrm { r } \left(\frac{\mathrm{v}^{2}}{4 \mathrm{a}^{2}}\right.\right. \\
\left.\left.+\frac{\mathrm{b}}{\mathrm{a}}\right)^{0,5}\right]
\end{gathered}
$$

gde je $\mathrm{K}_{0}$ modifikovana Beselova funkcija II vrste i nultog reda.

Nakon razvijanja jednačine (5) za 3D Rozentalov model dobija se jednačina (6) koja definiše vezu kritičnog vremena hlađenja i temperature predgrevanja. Izrazom (1) je prikazana formula za izračunavanje, odnosno uspostavljanje relacije, sa temperaturom predgrevanja za 3D model zavarivanja. Zbog odstupanja u izračunavanju pronađen je izraz (7) od strane British Standard [32] koji je tačniji

$$
\begin{aligned}
t_{8,5}=\frac{Q}{2 \pi \lambda} & {\left[\frac{1}{500-T_{p}}-\frac{1}{800-T_{p}}\right] } \\
t_{8,5}=(6700- & \left.5 T_{p}\right) \times Q x\left[\frac{1}{500-T_{p}}\right. \\
& \left.-\frac{1}{800-T_{p}}\right],
\end{aligned}
$$

gde su d debljina ploča koje se zavaruju, $Q$ uneta toplota, $T_{p}$ temperatura predgrevanja $\mathrm{i}_{8 / 5}$ vreme hlađenja između temperatura $800^{\circ} \mathrm{C}$ i $500^{\circ}$.

Jednačina (6) razvijena kod elektrolučnog zavarivanja nije u praksi davala najtačnije rezultate te je stoga urađena približnija formula za 3D model, usvojena prema standardu EN 1102-2, prikazana relacijom (7). Promenljive imaju dimenzije

$\lambda$ - termička provodnost $\mathrm{u}\left[\mathrm{Js}^{-1} \mathrm{~m}^{-10} \mathrm{C}^{-1}\right] \quad \mathrm{i} \quad c$ specifična toplota $\mathrm{u}\left[\mathrm{Jkg}^{-1}{ }^{\circ} \mathrm{C}^{-1}\right]$.

Zna se da je $Q=\frac{q}{v}$, gde je q kod elektrolučnog zavarivanje $=U I \eta, U$ je napon zavarivanja $\mathrm{u}[\mathrm{V}] \mathrm{a}$ I jačina struje kod elektrolučnog zavarivanja u $[A] \mathrm{i}$ $\eta$ koeficijent iskoriscenja pri zavarivanju, zavistan od vrste zavarivanja. $Q$ je ulazna kolicina toplote za određenu brzinu u [kJ/mm].

\section{Proračun kritičnog vremena hlađenja $t_{8 / 5}$ za} 3D model zavarivanja

Za ovo izračunavanje ćemo jednačinu predstaviti u obliku

$$
\begin{aligned}
\frac{t_{8,5}}{Q}=(6700 & \left.-5 T_{p}\right)\left[\frac{1}{500-T_{p}}\right. \\
& \left.-\frac{1}{800-T_{p}}\right]
\end{aligned}
$$

Desna strana jednačine (8) je zavisna samo od temperature $T_{p}$, te možemo vrednosti predstaviti na apscisnoj osi a leva strana iste jednačine na ordinatnoj osi. Tako za 3D model se može naći rešenje za vreme hlađenja i temperaturu predgrevanja u obliku grafičkom i analitičkom.

\subsection{Grafičko rešenje za 3D model prezentacije kod elektrolučnog zavarivanja}

Uradimo grafik funkcije predstavljene relacijom (8) tako da se leva strana jednačine nanosi na ordinatnu osu a desna na apscisnu osu. Grafik je dat na slici 2.

Primer 2: Ako je vrednost vremena hlađenja 20 [s] i količina unete toplote $1,5[\mathrm{~kJ} / \mathrm{mm}]$, naći temperaturu predgrevanja.

Nalaženjem odnosa $t_{8,5} / Q$ dobija se vrednost 13,33 , onda se povlači sa ordinatne ose prava sa tom vrednošu sve do grafika na sl.2, a od presečne tačke spušta do apscisne ose. $U$ konkretnom 
slučaju se dobija vrednost za temperaturu predgrevanja u iznosu od $235\left[{ }^{\circ} \mathrm{C}\right]$. Moguć je i obrnut slučaj kada se zna vrednost temperature predgrevanja kod elektrolučnog zavarivanju da se pronađe kritično verme hlađenja $t_{8 / 5}$.

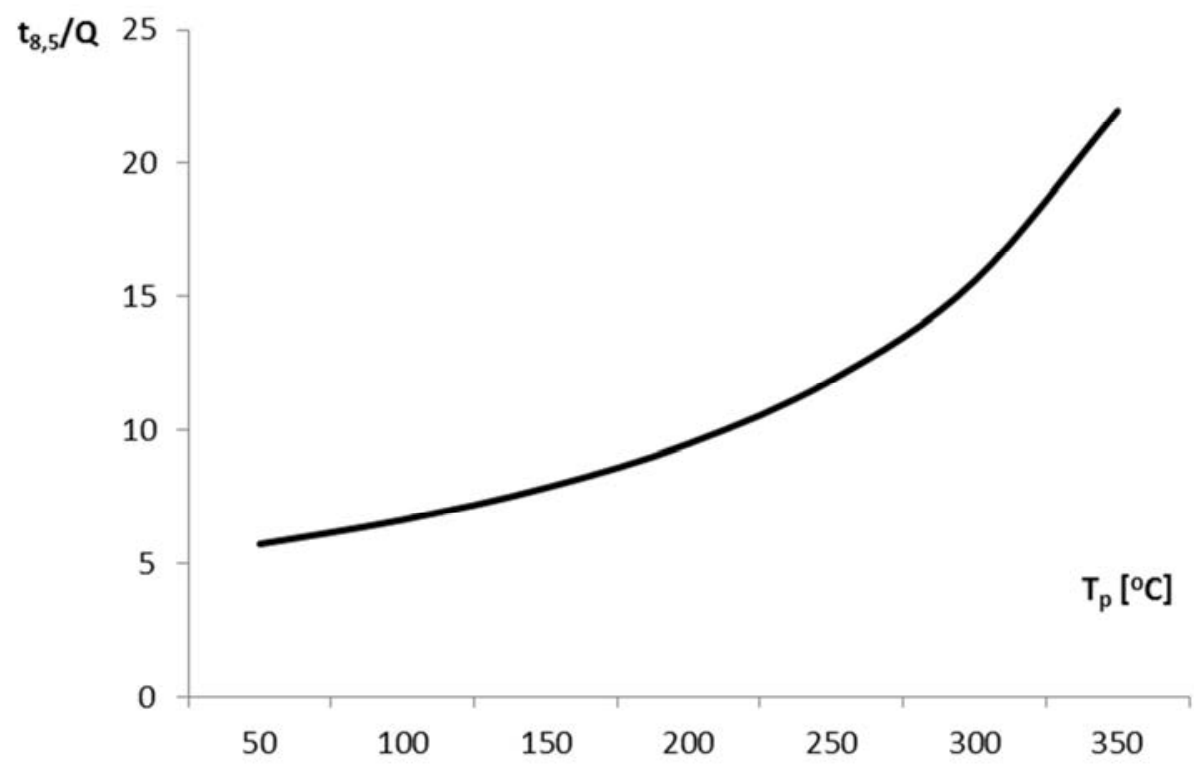

SI.2. Grafička zavisnost za izračunavanje veličina kod elektrolučnog zavarivanja kod 3D modela

2.2 Analitičko nalaženje vrednosti veličina Kod elektrolučnog zavarivanja 3D modela

Uvedimo smenu oblika

$$
C_{1}=\frac{t_{8,5}}{Q}
$$

tako da će jednačina (8) se transformisati u

$$
\begin{aligned}
\mathrm{C}_{1}\left[\left(500-\mathrm{T}_{\mathrm{p}}\right)\right. & \left.\left(800-\mathrm{T}_{\mathrm{p}}\right)\right] \\
= & 300\left(6700-5 \mathrm{~T}_{\mathrm{p}}\right)
\end{aligned}
$$

Ovde, kod ove vrste zavarivanja nećemo rešavati putem aproksimacije zato što se prethodna jednačina svodi na kvadratnu jednačinu. $\mathrm{Na}$ taj način možemo naći tačno rešenje, te uvodimo još jednu smenu oblika

$$
C_{2}=\frac{Q}{t_{8,5}}
$$

Svođenjem jednačina (9), (10) i (11) dobija se kvadratna jednačina čije je rešenje oblika

$\mathrm{Tp}_{1 / 2}=10^{3}\left[0,75 \mathrm{C}_{2}-0,65 \pm\left[\left(1.5 \mathrm{C}_{2}-1.3\right)^{2}\right.\right.$ $\left.-0.4\left(4-20.1 C_{2}\right)\right]^{0.5}$

Ovim je prikazano analitičko i grafičko rešavanje relevantnih veličina 3D modela kod elektrolučnog zavarivanja, što omogućava istraživačima i teoretičarima iz oblasti termike da lakše i brže proračunavaju veličine radi optimizacije zavarivanja.

\section{Diskusija i prikaz rezultata u odnosu na postojeća rešenja}

Za izračunavanje temperature predgrevanja $T_{p} \quad i$ vremena hlađenja $t_{8 / 5}$ postoje dve grupe rešenja $i$ to
2D i 3D model. Koji će se model uzimati u obzir kod izračunavanja ispitivaće se vrednost kritične debljine koja se izračunava po formuli (13). Kada je debljina trake koja se zavaruje $u$ postupku elektrolučnog zavarivanja veća od vrednosti $d_{g r}$ iz (13) onda će se primenjivati 3D model za koji važe formule (6) i (7). U suprotnom se primenjuju formule za 2D model izračunavanja koje nisu predmet analize u ovom radu. $U$ nekoj literaturi se ove formule nazivaju Rozentalovim $i$ one su usvojene u standardu EN 1102-2.

Izračunavanje po ovim formulama stvara velike probleme jer se po samom izgledu formula, vidi da je temperatura predgrevanja nezavisno promenljiva i kao takva bi trebalo da se unapred zna. To je nemoguće jer se za svaku vrstu čelika mora unapred znati određena vrednost za kritično vreme hlađenja a po literaturi [15], se podrazumeva čak i predistorija proizvodnje čelika. Znači, vreme $t_{8 / 5}$ je ono vreme kada se temperatura zavarivanja od tačke zavarivanja smanjuje od $800{ }^{\circ} \mathrm{C}$ do $500{ }^{\circ} \mathrm{C}$. $\mathrm{U}$ radovima [ 28,31$]$ se primenjuje indirektno procenjivanje putem simulacija, negde uzimaju podaci sa eksperimenta, odnosno unapred se zadaje temperatura predgrevanja i izračunava vreme hlađenja.To ne stvara mogućnost posedovanja stalnog algoritma određivanja ovih ključnih dveju ključnih veličina, veoma bitnih za kvalitet zavarivanja finalnih proizvoda.

$$
\mathrm{d}_{\mathrm{gr}}=\left[\frac{\mathrm{Q}}{\rho \mathrm{c}}\left(\frac{1}{500-\mathrm{T}_{\mathrm{p}}}\right)+\left(\frac{1}{800-\mathrm{T}_{\mathrm{p}}}\right)\right]^{0,5}
$$


Zato je istraživanjem u ovom radu se došlo na ideju da se prekomponuju jednačine (6) i (7), tako da će imati oblik (8) i (12). Takvim jednačinama je omogućeno grafičko predstavljanje odakle se na osnovu poznatih ulaznih veličina zavarivanja izračunava nepoznata kao što su temperatura predgrevanja ili vreme hlađenja. Takav način estimacije pruža mogućnost primene i u teoriji i u praksi na posve jednostavan način. Numerički rezultati iz ovog rada su upoređeni sa nekim primerima iz radova [29-30], čime je pored originalnosti i jednostavnosti izračunavanja utvrđena verodostojnost i tačnost rezultata autora ovog rada. Istraživanjem je utvrđeno da rezultati u radu [31] za sve primere znatno odstupaju u odnosu na egzaktne rezultate. Primenom algoritma iz ovog rada se izbegavaju pogreške i stvara uslov da se projektuje zavarivanje sa kontrolobalnim kvalitetom.

\section{Zaključak}

$U$ radu se nakon analiziranih problema $u$ teoriji $i$ praksi izračunavanja temperature predgrevanja i kritičnog vremena hlađenja kod elektrolučnog zavarivanja prišlo jednom novom pristupu rešavanja i poboljšanja algoritma. Postojeća jednačina za 3D Rozentalov model za izračunavanje i predstavljanje vremena hlađenja $t_{8 / 5} \quad \mathrm{i}$ temperatura predgrevanja $T_{p}$, je dekomponovana.

Takvim pogodnim prikazom i oblikom jednačine su omogućile da se uvede grafoanalitičko predstavljanje i izračunavanje. Pored toga, omogućeno je numeričko izračunavanje navedenih karakterističnih i bitnih veličina za 3D model egzaktnom formulom.

Ovakav pristup je primenjen da bi se omogućilo izračunavanje potrebnih veličina na prost $\mathrm{i}$ brz način.

Cilj autora ovog rada je da da prikaz svojih inoviranih primenjenih i teorijskih istraživanja, iz oblasti elektrolučnog zavarivanja čeličnih materijala, svetskoj stručnoj i naučnoj javnosti na korišćenje i kritičko sagledavanje, na čemu će im biti veoma zahvalni.

\section{Popis oznaka}

\begin{tabular}{|c|c|}
\hline $\mathrm{d}$ & debljina zavarivanja, $[\mathrm{mm}]$ \\
\hline $\mathrm{Q}$ & količina unete toplote, $[\mathrm{kJ} / \mathrm{mm}]$ \\
\hline $\mathrm{T}_{\mathrm{p}}$ & temperatura predgrevanja, $\left[{ }^{\circ} \mathrm{C}\right]$ \\
\hline $\mathrm{t}_{8 / 5}$ & kritično vreme hlađenja, $[\mathrm{s}]$ \\
\hline $\mathrm{V}$ & brzina zavarivanja, $[\mathrm{mm} / \mathrm{s}]$ \\
\hline $\mathrm{U}$ & napon luka, $[\mathrm{V}]$ \\
\hline $\mathrm{I}$ & jačina struje zavarivanja, $[\mathrm{A}]$ \\
\hline$\lambda$ & termička provodnost, $\left[\mathrm{Jkg}^{-1}{ }^{\circ} \mathrm{C}^{-1}\right]$ \\
\hline$\rho$ & specifična težina, $\left[\mathrm{kgm}^{-3}\right]$ \\
\hline $\mathrm{C}$ & specifična toplota, $\left[\mathrm{Jkg}^{-1}{ }^{\circ} \mathrm{C}^{-1}\right]$ \\
\hline$\eta$ & koeficijent iskoriščenja \\
\hline
\end{tabular}

\section{LITERATURA}

1. Simpson P.G.,Induction Heating - Coil and System Design,Mc Graw Hill,sNew York, USA, p.304,1960

2. Welding Handbook, Vol. 3, 7th ed., American Welding Society, Miami, FL, 1980,pp. 170-238.

3. Mendez, P. F., and Eagar, T. W., Advanced Materials and Processes, 159: 39,2001.

4. Welding Handbook, Vol. 1, 7th ed., American Welding Society, Miami, FL, 1976,pp. 2-32.

5. Welding Workbook, Data Sheet 212a, Weld. J., 77: 65, 1998.

6. Welding Handbook, Vol. 2, 7th ed., American Welding Society, Miami, FL, 1978,pp. 78-112, 296-330.
7. Lyttle, K. A., in ASM Handbook, Vol. 6, ASM International, Materials Park, OH,1993, p. 64.

8. Schwartz, M. M., Metals Joining Manual, McGraw-Hill, New York, pp. 2-1 to3-40.,1979

9. Lesnewich, A., in Weldability of Steels, 3rd ed., Eds. R. D. Stout and W. D. Doty,

10. Welding Handbook,Ninth Edition, Volume 4,Materials and Applications, Part 1, American Welding Society, Annette O'Brien Editor,Miami, FI, USA,p.860,2011

11. Sindo Kou, Welding Metallurgy, Second Edition,Wiley-Interscience,Hobeken, New Jersey, USA,p.466,2003 
12. D. Gulaev: Impovements of production technologies and quality of electrically welded tubes, (Kiev, Tehnika) p.p. 4-116,1984

13. Choong/Mzeoung Kim, POSCO, Zong-Seong Kim, Hong Ik University; Korea, Tube and Pipe Technology, January/February, (2001)

14. Suzuki S., Takamme T., " The Formation Mechanism of White Line Welded Joints of ERW Steel Pipes", Tetsu to Hagane, Vol.40, No 10,(1984) p.p.153-159

15. H. Schuman: Metallography, Leipzig, VEB Deutcher Verlag fur Grunstoffindustrie (1989)

16. Gaultois M.W., Ph.D. thesis, Design Principles for Oxide Thermoelectric Materials, University of Califoornia, Santa Barbara, USA,2015

17. Hyungsuk K., Ph.D. Thesis, Magnetoelectric Effect and Magnetodielectric Effect in Magnetic Nanoparticles, University of California, Los Angelos, USA

18. Rosenthal, D., Weld. J., 20: 220s, 1941.

19. Rykalin,N.N., Calculation of Heat Flow in Welding, Trans. Z. Paley and C. M.Adams,Jr., Document 212-350-74, 1974, International Institute of Welding,

20. Rykalin, N. N., Nikolaev, A. V. Welding Kod elektrolučnog Heat Flow. // Welding in the World, 9, 3/4(1971), pp.112-132.

21. Rosenthal, D. The Theory of Moving Source of Heat and its Application to Metal Transfer. // Transations ASME, 43, 11(1946), pp. 849-866.

22. Christensen B.N.,Davies V.D.L.,Gjermundsen K.,Distribution of temperatures in kod elektrolučnog welding, British Welding Journal, February (1965), p.p. 54 to 75

23. Milićević M., The Application of a New Formula of Nakaoka Coefficient in HF Inductive Welding, Journal of Mechanical Engineering 56 (2010), 7-8,p.p. 483-488
24. Milićević,M., Stoiljković,I., Jovanović,T., Nejković,V., Opis nedostataka feritnog koncentratora kod visokofrekventnog induktivnog zavarivanja,Zavarivanje i zavarene konstrukcije,br.3, 2013 god., Beograd

25. Milićević, S.M., Jovanović, M.T., Nejković, M.V.,Kako smo izumeli najbolji magnetni koncentrator na svetu za visokofrekventno zavarivanje,Zavarivanje i zavarene konstrukcije,br.2, 2014 god.,Beograd

26. Milićević S.M., Stojanović M,T., Stanković V., Nejković M.V.,Computers regulation HF inductive welding, Zavarivanje i zavarene konstrukcije, br.3, 2015 god., Beograd

27. Milićević S.M., Stojanović M,T., Stanković V., Nejković M.V.,,Contribution to contact temperature mesurement,Welded $\$$ welded structures, br.2,2016,Beograd,pp.63-70

28. Poorhaydari K., Patchett B.M., Ivey D.G., Estimation of Cooling Rate in the Welding of Plates with Intermediate Thickness, Welding Journal, October (2006), p.p. 149 to155

29. Lazic, V. N.,et al, Theoretical-Experimental Determining of Cooling Time $(\mathrm{T}(8 / 5))$ in Hard Facing of Steels for Forging Dies, Thermal Science, 14, (2010), 1, pp. 235-246

30. Lazic, V. N., et al.: Numerical Analysis of Temperature Field During Hardfacing... Thermale Science:Vol. 18, Suppl. 1, (2014),pp.113-120

31. Meseguer-Valdenebro, J.L. et al.: Calculation of t8/5 by Response Surface... Termale Science:Vol. 18, Suppl. 1,(2014), pp. S149 S158

32. Standard EN 1011 - 2/2007: Zavarivanje Preporuke za zavarivanje metalnih materijala Deo2: Elektrolučno zavarivanje feritnih čelika 